\title{
On Solving Fuzzy investment Problem using Dynamic Programming
}

\author{
Hussah Mohammad Almenderj \\ Mathematics Department, College of Arts and Science \\ Al- Badaya, Qassim University \\ Qassim, Saudi Arabia
}

\begin{abstract}
Investment problem is considered as one of the most important and interesting optimization problem. This problem becomes more difficult when we deal with it in an uncertain and vague environment with fuzzy data. The aim of this paper is to modify the investment problem with Intervalvalued fuzzy number instead of normal fuzzy numbers. While the Interval- valued fuzzy number investment problem introduced, a dynamic programming is applied to obtain the optimal policy and the corresponding best return. A numerical example is given to illustrate the aspects of the considered problem.
\end{abstract}

\section{Keywords}

Investment problem; Interval- valued fuzzy number; Signed distance ranking; Dynamic programming; Optimal policy; Best return.

\section{INTRODUCTION}

Investment plays an important social role in helping severs to meet their financial needs over time and, in doing so, the investment process contributes to growth through the efficient allocation of capital. In active management, the investment processes depends on research to identify opportunities riskadjusted return over client's chosen time horizons. Research used in investment process can take many different forms and can be sourced from multiple locations. Meza and Webb [14] examined the effects of symmetric information on aggregate investment and the financial structure of firms. Hargitay [8] identified the property of portfolio problem in order to have the way for the applications of recent developments in investment and portfolio theory. Yahaya [20] introduced a procedure for obtaining an optimal solution to the Markowitz's mean- variance portfolio selection problem based on the analytical solution developed in previous research that lead to the convergence of an important model known as the Black Model. Yahaya et al.[21] compared investment opportunities and combined them with portfolios.

In many scientific areas, such as systems analysis and operations research, a model has to be set makes this possible. Fuzzy numerical data can be represented by means of fuzzy subsets of the real line, known as fuzzy numbers. Dubois and Prade [7] extended the use of algebraic operations on real numbers to fuzzy numbers by the use of a fuzzification principle. Jana et al. [10] added an entropy objective function to the multiobjective portfolio selection model that is to generate a well diversified asset portfolio based on the possibilities mean value and variance of constraints distribution.. Ammar and Khalifa [2] introduced fuzzy portfolio selection problem as quadratic programming approach. Ammar and Khalifa [2] presented portfolio selection problem as quadratic programming problem with inexact rough interval in the objective function and constraints. Khalifa and ZeinEldein [14] presented portfolio selection problem as multi- objective quadratic- linear programming problem with fuzzy objective functions coefficients and applied fuzzy programming approach for solution. By addressing randomness in the project costs and making individual project budgets decision variables, $\mathrm{Hu}$ and Szmerekovsky [9] introduced the problem of balancing associated with budgetary slack and cost overruns in the portfolio selection problem. In the presence of transaction costs, Suh [17] proposed a new portfolio selection problem rule formed by combining an extant portfolio rule with the norebalancing portfolio rule. Abel and Eberly [1] unified an investment model under uncertainty in a dynamic programming problem. Ammar and Khalifa [3] characterized the optimal solution on uncertainty investment problem with trapezoidal fuzzy numbers. Kahraman et al.[11] applied dynamic programming to the situation where each investment in the set has several possible values, and the rate of return varies with the amount invested. Modarres et al. [15] used a dynamic programming approach to obtain the optimal policies for an investor who faces as stochastic number of investing chances (with Poisson Distribution) and a stochastic profit for every chance accruing (with Uniform Distribution). Xu[19] developed new two- stage fuzzy optimization methods for production and financial investment planning problem, in which the exchange rate is uncertain and characterized by possibility distribution. Sirbiladze et al.[16] introduced new methodology of making a decision on an optimal investment in several projects. Ammar and Khalifa [4] studied investment problem with rough interval data and applied the dynamic programming for obtaining the optimal policy and the corresponding best return. Tahar et al.[18] presented an extension of the Merton optimal investment problem to the case where the risk asset is subject to transaction costs and capital gains taxes.

This paper deals with the investment problem involving interval- valued fuzzy numbers. Here, we use the interval valued fuzzy numbers instead of normal fuzzy numbers and a dynamic programming approach is applied to obtain the optimal policy and the corresponding best return. A numerical example is given to illustrate the aspects of the development results.

The remainder of the paper is as follows: In section2, some preliminaries needed in the sake of the paper are introduced Section 3 introduces the investment problem with interval valued fuzzy numbers. In section 4 , a numerical example is given to clarify the obtained results. Finally, some concluding remarks are reported in section5. 


\section{PRELIMINARIES}

In this section, fundamental definition of fuzzy number and interval- valued fuzzy numbers and their arithmetic operations introduced by Chiang [6] and Kauffmann and Gupta, [12]) are reviewed.

\subsection{Definition1}

Let $R$ be the set of real numbers, the fuzzy number $\tilde{p}$ is a mapping $\mu_{\tilde{a}}: R \rightarrow[0,1]$, with the following properties:

(a) $\mu_{\tilde{p}}(x)$ is an upper semi- continuous membership function;

(b) $\tilde{p}_{\text {is }}$ a convex set, i. e., $\mu_{\tilde{p}}\left(\lambda x^{1}+(1-\lambda) x^{2}\right) \geq \min \left\{\mu_{\tilde{p}}\left(x^{1}\right), \mu_{\tilde{p}}\left(x^{2}\right)\right\}$, for all

$x^{1}, x^{2} \in R, 0 \leq \lambda \leq 1$

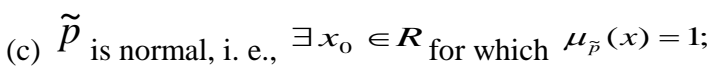

(d) $\quad \operatorname{Supp}^{(\tilde{p})=\left\{x: \mu_{\tilde{p}}(x)>0\right\}}$ is the support of a fuzzy set $\tilde{p}$.

\subsection{Definition2}

A triangular fuzzy number is defined by a triplet, whose membership function is defined as follows:

$$
\mu_{\tilde{A}}(x)=\left\{\begin{array}{lr}
0, & x<a_{1}, \\
\frac{x-a_{1}}{a_{2}-a_{1}}, & a_{1} \leq x \leq a_{2}, \\
\frac{a_{3}-x}{a_{3}-a_{2}}, & a_{2} \leq x \leq a_{3}, \\
0, & x>a_{3},
\end{array}\right.
$$

\subsection{Definition3}

If the membership function of the fuzzy set $\widetilde{P}$ on $R$ is

$\mu_{\widetilde{P}}(x)=\left\{\begin{array}{lr}0, & x<a_{1}, \\ \frac{\alpha\left(x-a_{1}\right)}{\left(q-a_{1}\right)}, & a_{1} \leq x \leq q, \\ \frac{\alpha\left(a_{3}-x\right)}{\left(a_{3}-q\right)}, & q \leq x \leq a_{3}, \\ 0, & x>a_{3},\end{array}\right.$

Where, $0<\alpha \leq 1$, so $\tilde{A}$ is said to be a level $\alpha$ fuzzy number and it is denoted as $\tilde{P}=\left(a_{1}, q, a_{3} ; \alpha\right)$.

\subsection{Definition4}

An interval- valued fuzzy set $\tilde{P}$ on $R$ is represented as $\tilde{P} \cong\left\{\left(x,\left[\mu_{P^{-}}(x), \mu_{P^{+}}(x)\right]\right): x \in R\right\}$,

where

$\mu_{P^{-}}(x), \mu_{P^{+}}(x) \in[0,1]$ and $\mu_{P^{-}}(x) \leq \mu_{P^{+}}(x) ; \forall x \in R \quad$ and is denoted as $\widetilde{P}=\left[\widetilde{P}^{-}, \widetilde{P}^{+}\right]$, which means that the grade of membership of $x$ belongs to the interval $\left\lfloor\mu_{P^{-}}(x), \mu_{P^{+}}(x)\right\rfloor$, the least grade of membership at $x$ is $\mu_{\tilde{P}^{-}}(x)$ and greatest grade of membership at $x$ is $\mu_{\tilde{P}^{+}}(x)$. Let

$\mu_{\tilde{P}^{-}}(x)=\left\{\begin{array}{cr}0, & x<a_{1}, \\ \frac{\alpha\left(x-a_{1}\right)}{\left(q-a_{1}\right)}, & a_{1} \leq x \leq q, \\ \frac{\alpha\left(a_{3}-x\right)}{\left(a_{3}-q\right)}, & q \leq x \leq a_{3}, \\ 0, & x>a_{3},\end{array}\right.$

Then, $\tilde{P}^{-}=\left(a_{1}, q, a_{3} ; \alpha\right)$. Let

$\mu_{\tilde{P}^{+}}(x)=\left\{\begin{array}{lr}0, & x<b_{1}, \\ \frac{\beta\left(x-b_{1}\right)}{\left(q-b_{1}\right)}, & b_{1} \leq x \leq q, \\ \frac{\beta\left(b_{3}-x\right)}{\left(b_{3}-q\right)}, & q \leq x \leq b_{3}, \\ 0, & x>b_{3},\end{array}\right.$

Then, $\widetilde{P}^{+}=\left(b_{1}, q, b_{3} ; \beta\right)$. Here, $0<\alpha \leq \beta \leq 1$ and $b_{1}<a_{1}<q<a_{3}<b_{3}$. Then interval- valued fuzzy set is:

$$
\tilde{P} \cong\left\{\left(x,\left[\mu_{P^{-}}(x), \mu_{P^{+}}(x)\right]\right): x \in R\right\}, \quad \text { and } \quad \text { is also }
$$

denoted as:

$\tilde{P}=\left[\left(a_{1}, q, a_{3} ; \alpha\right),\left(b_{1}, q, b_{3} ; \beta\right)\right]=\left[\tilde{P}^{-}, \tilde{P}^{+}\right] \tilde{P}$ is called a level $(\alpha, \beta)$ interval- valued fuzzy number

\subsection{Definition5}

$$
{ }^{\text {Let }} F_{I V F N}(\alpha, \beta)=\left\{\begin{array}{l}
{\left[\left(a_{1}, q, a_{3} ; \alpha\right),\left(b_{1}, q, b_{3} ; \beta\right)\right]} \\
: \forall b_{1}<a_{1}<q<a_{3}<b_{3}, 0<\alpha \leq \beta \leq 1
\end{array}\right\} \text {, }
$$

by the family of $(\alpha, \beta)$ interval- valued fuzzy numbers, $\widetilde{P}=\left[\left(a_{1}, q, a_{3} ; \alpha\right),\left(b_{1}, q, b_{3} ; \beta\right)\right] \in F_{I V F N}(\alpha, \beta), \quad$ and $\widetilde{Q}=\left[\left(c_{1}, r, c_{3} ; \alpha\right),\left(d_{1}, r, d_{3} ; \beta\right)\right] \in F_{I V F N}(\alpha, \beta)$ be two interval- valued fuzzy numbers. The arithmetic operations of interval- valued fuzzy numbers $\widetilde{P}$ and $\widetilde{Q}$ are defined as:

(i) $\tilde{P}(+) \tilde{Q}=\left[\left(a_{1}+c_{1}, q+r, a_{3}+c_{3} ; \alpha\right),\left(b_{1}+d_{1}, q+r, b_{3}+d_{3} ; \beta\right)\right]$

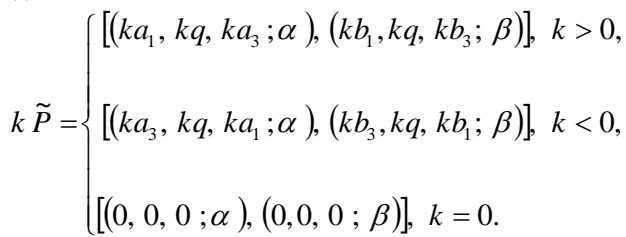

\subsection{Definition6}

Let

$\widetilde{P}=\left[\left(a_{1}, q, a_{3} ; \alpha\right),\left(b_{1}, q, b_{3} ; \beta\right)\right] \in F_{I V F N}(\alpha, \beta), 0<\alpha \leq \beta \leq 1$. 
So, the signed distance of $\tilde{P}_{\text {from }} \tilde{0}_{(y-a x i s)}$ is given as:

$$
d_{0}(\tilde{P}, \tilde{0})=\frac{1}{8}\left(6 q+a_{1}+a_{3}+4 b_{1}+4 b_{3}+3\left(2 q-b_{1}-b\right) \frac{\alpha}{\beta}\right) .
$$

Remark1. Let $\widetilde{\boldsymbol{P}}=\left[\left(a_{1}, q, a_{3} ; \alpha\right),\left(b_{1}, q, b_{3} ; \beta\right)\right] \quad$ and $\widetilde{Q}=\left[\left(c_{1}, r, c_{3} ; \alpha\right),\left(d_{1}, r, d_{3} ; \beta\right)\right] \in F_{I V F N}(\alpha, \beta)$. Then:

(1) $d_{0}(\widetilde{P}(+) \widetilde{Q}, \widetilde{\mathrm{O}})=d_{0}(\widetilde{P}, \widetilde{\mathrm{O}})+d_{0}(\widetilde{Q}, \widetilde{\mathrm{O}})$,

(2) $d_{\mathrm{o}}(k \widetilde{P}, \widetilde{\mathrm{O}})=k d_{\mathrm{o}}(\widetilde{P}, \widetilde{\mathrm{O}}), k>0$.

It is clear that from remark1, the signed distance ranking is a linear ranking on $F_{I V F N}(\alpha, \beta)$.

\subsection{Definition7.}

For each $0<\alpha \leq \beta \leq 1$, let $\tilde{P}, \tilde{Q} \in F_{I V F N}(\alpha, \beta)$. The ranking of level $(\alpha, \beta)$ interval- valued fuzzy numbers in $F_{I V F N}(\alpha, \beta)$ using the signed distance function defined in (1) is defined as:

- $\quad \tilde{Q} \pi \tilde{P}$ If and only if $d_{0}(\widetilde{Q}, \widetilde{\mathrm{O}})<d_{0}(\widetilde{P}, \widetilde{\mathrm{O}})$,

- $\quad \tilde{Q} \approx \tilde{P}$ If and only if $d_{0}(\tilde{Q}, \tilde{0})=d_{0}(\widetilde{P}, \tilde{0})$.

Before, a problem definition is introduced, let us consider the following notation:

Notation:

We now define:

$f_{1}(x)$ : Profit function with investment in policy 1,

$f_{2}(x)$ : Profit function with investment in policy 2 ,

$f_{N}(x)$ : Profit function with investment in policy $N$,

$$
\gamma_{1,2}(l): \text { Return on combined investment in policy } 1
$$
and 2 ,

$\gamma_{1,2,3}(l):$ Return on combined investment in policy 1 , 2 and 3 ,

$\gamma_{1,2,3, \ldots, N}(l):$ Return on combined investment in policy $1,2,3 \ldots$ and $N$.

$l$ : Amount of investment.

\section{PROBLEM DEFINITION}

Assume that we have disposal $\$ \mathrm{M}$ for investment in $\mathrm{N}$ possible production programs $S_{1}, S_{2}, \ldots, S_{N}$. The expected profits for a period $\mathrm{k}$ years are not known, but they will be estimated and given in the ${ }^{(\alpha, \beta)}$ interval-valued fuzzy numbers form.

A dynamic programming is being used here through the use of signed distance ranking function defined in (1), so as to obtain the best return.

Captions should be Times New Roman 9-point bold. They should be numbered (e.g., "Table 1" or "Figure 2"), please note that the word for Table and Figure are spelled out. Figure's captions should be centered beneath the image or picture, and Table captions should be centered above the table body.

\section{NUMERICAL EXAMPLE}

Consider one investor has at his disposal $\$ 10$ millions for investment in four possible production programs $S_{1}, S_{2}, S_{3}$, and $S_{4}$. The expected profit for 3 years given in the $(\alpha, \beta)$ interval- valued fuzzy numbers as shown in the following table

Table1. Return on an investment for a period of three years

\begin{tabular}{|c|c|}
\hline $\begin{array}{c}\text { Investment } \\
\times 10^{6}\end{array}$ & $\begin{array}{c}\text { Profit } \\
\text { investing in }\end{array}$ \\
\hline 0 & 0 \\
\hline 1 & {$[(0.26,0.28,0.29 ; 0.3),(0.25,0.28,0.30 ; 0.6)]$} \\
\hline 2 & {$[(0.42,0.45,0.46 ; 0.3),(0.40,0.45,0.47 ; 0.6)]$} \\
\hline 3 & {$[(0.60,0.65,0.68 ; 0.3),(0.58,0.65,0.71 ; 0.6)]$} \\
\hline 4 & {$[(0.73,0.78,0.80 ; 0.3),(0.70,0.78,0.85 ; 0.6)]$} \\
\hline 5 & {$[(0.85,0.90,0.95 ; 0.3),(0.81,0.90,1.01 ; 0.6)]$} \\
\hline 6 & {$[(0.98,1.02,1.05 ; 0.3),(0.95,1.02,1.11 ; 0.6)]$} \\
\hline 7 & {$[(1.06,1.13,1.14 ; 0.3),(1.04,1.13,1.16 ; 0.6)]$} \\
\hline 8 & {$[(1.21,1.23,1.28 ; 0.3),(1.20,1.23,1.30 ; 0.6)]$} \\
\hline 9 & {$[(1.29,1.32,1.35 ; 0.3),(1.28,1.32,1.42 ; 0.6)]$} \\
\hline 10 & {$[(1.36,1.38,1.40 ; 0.3),(1.35,1.38,1.50 ; 0.6)]$} \\
\hline
\end{tabular}


Continue

\begin{tabular}{|c|c|}
\hline $\begin{array}{c}\text { Investment } \\
\times 10^{6}\end{array}$ & $\begin{array}{c}\text { Profit } \\
\text { investing in }\end{array}$ \\
\hline 0 & 0 \\
\hline 1 & {$[(0.23,0.25,0.26 ; 0.3),(0.20,0.25,0.28 ; 0.6)]$} \\
\hline 2 & {$[(0.35,0.41,0.42 ; 0.3),(0.33,0.41,0.43 ; 0.6)]$} \\
\hline 3 & {$[(0.50,0.55,0.57 ; 0.3),(0.48,0.55,0.60 ; 0.6)]$} \\
\hline 4 & {$[(0.63,0.65,0.66 ; 0.3),(0.62,0.65,0.67 ; 0.6)]$} \\
\hline 5 & {$[(0.70,0.75,0.76 ; 0.3),(0.68,0.75,0.77 ; 0.6)]$} \\
\hline 6 & {$[(0.75,0.80,0.85 ; 0.3),(0.70,0.80,0.90 ; 0.6)]$} \\
\hline 7 & {$[(0.84,0.85,0.86 ; 0.3),(0.83,0.85,0.90 ; 0.6)]$} \\
\hline 8 & {$[(0.86,0.88,0.89 ; 0.3),(0.85,0.88,0.90 ; 0.6)]$} \\
\hline 9 & {$[(0.89,0.90,0.91 ; 0.3),(0.88,0.90,0.93 ; 0.6)]$} \\
\hline 10 & {$[(0.89,0.90,0.92 ; 0.3),(0.88,0.90,0.94 ; 0.6)]$} \\
\hline & \\
\hline
\end{tabular}

Continue

\begin{tabular}{|c|c|}
\hline $\begin{array}{c}\text { Investment } \\
\times 10^{6}\end{array}$ & $\begin{array}{c}\text { Profit } \\
\text { investing in }\end{array}$ \\
\hline 0 & 0 \\
\hline 1 & {$[(0.14,0.15,0.17 ; 0.3),(0.13,0.15,0.18 ; 0.6)]$} \\
\hline 2 & {$[(0.20,0.25,0.26 ; 0.3),(0.19,0.25,0.27 ; 0.6)]$} \\
\hline 3 & {$[(0.39,0.40,0.41 ; 0.3),(0.37,0.40,0.42 ; 0.6)]$} \\
\hline 4 & {$[(0.47,0.50,0.51 ; 0.3),(0.540 .50,0.52 ; 0.6)]$} \\
\hline 5 & {$[(0.55,0.62,0.64 ; 0.3),(0.53,0.62,0.66 ; 0.6)]$} \\
\hline 6 & {$[(0.71,0.73,0.74 ; 0.3),(0.70,0.73,0.75 ; 0.6)]$} \\
\hline 7 & {$[(0.78,0.82,0.83 ; 0.3),(0.76,0.82,0.84 ; 0.6)]$} \\
\hline 8 & {$[(0.89,0.90,0.93 ; 0.3),(0.88,0.90,0.95 ; 0.6)]$} \\
\hline 9 & {$[(0.95,0.96,1.00 ; 0.3),(0.93,0.96,1.02 ; 0.6)]$} \\
\hline 10 & {$[(0.99,1.00,1.04 ; 0.3),(0.97,1.00,1.08 ; 0.6)]$} \\
\hline
\end{tabular}

Continue

\begin{tabular}{|c|c|}
\hline $\begin{array}{c}\text { Investment } \\
\times 10^{6}\end{array}$ & Profit investing in $S_{4}$ \\
\hline 0 & 0 \\
\hline 1 & {$[(0.19,0.20,0.22 ; 0.3),(0.18,0.20,0.24 ; 0.6)]$} \\
\hline 2 & {$[(0.27,0.31,0.32 ; 0.3),(0.25,0.31,0.33 ; 0.6)]$} \\
\hline 3 & {$[(0.33,0.42,0.45 ; 0.3),(0.31,0.42,0.48 ; 0.6)]$} \\
\hline 4 & {$[(0.40,0.41,0.49 ; 0.3),(0.38,0.41,0.52 ; 0.6)]$} \\
\hline 5 & {$[(0.51,0.53,0.54 ; 0.3),(0.50,0.53,0.55 ; 0.6)]$} \\
\hline 6 & {$[(0.54,0.56,0.57 ; 0.3),(0.53,0.56,0.58 ; 0.6)]$} \\
\hline 7 & {$[(0.56,0.58,0.59 ; 0.3),(0.55,0.58,0.60 ; 0.6)]$} \\
\hline 8 & {$[(0.59,0.60,0.61 ; 0.3),(0.57,0.60,0.62 ; 0.6)]$} \\
\hline
\end{tabular}




\begin{tabular}{|c|c|}
\hline 9 & {$[(0.58,0.60,0.62 ; 0.3),(0.57,0.60,0.63 ; 0.6)]$} \\
\hline 10 & {$[(0.58,0.60,0.63 ; 0.3),(0.57,0.60,0.64 ; 0.6)]$} \\
\hline
\end{tabular}

We will now define:

$f_{1}(x)$ : The profit function for investing in $S_{1}$,

$f_{2}(x)$ : The profit function for investing in $S_{2}$,

$f_{3}(x)$ : The profit function for investing in $S_{3}$,

$f_{4}(x):$ The profit function for investing in $S_{4}$,

$\gamma_{1,2}(l):$ The optimal profit where $l$ is invested in $S_{1 \text { and }} S_{2}$ together,

$\gamma_{1,2,3}(l):$ The optimal profit where $l$ is invested in $S_{1}, S_{2}$ and $S_{3}$ together,

$\gamma_{1,2,3,4}(l)$ : The optimal profit where $l_{\text {is invested in }} S_{1}, S_{2}, S_{3}$ and $S_{4}$ together,

Let us now introduce the computation of the optimal profits in investments in $S_{1}$ and $S_{2}$ for various values of $l$ as:

$$
\gamma_{1,2}(l)=\underset{x+y=l}{\operatorname{Max}}\left(f_{1}(x)(+) f_{2}(x)\right) .
$$

Maximum return can be computed using the signed distance ranking defined in (1). The results of these computations are given in the following table.

Table2. Optimal policy investments $S_{1}$ and $S_{2}$

\begin{tabular}{|c|c|c|}
\hline Investment $\times 10^{6}$ & $\gamma_{1,2}(l)$ & $\begin{array}{c}\text { Optimal Policy with } S_{1 \text { and }} \\
S_{2}\end{array}$ \\
\hline 0 & 0 & $(0,0)$ \\
\hline 1 & {$[(0.26,0.28,0.29 ; 0.3),(0.25,0.28,0.30 ; 0.6)]$} & $(1,0)$ \\
\hline 2 & {$[(0.49,0.53,0.55 ; 0.3),(0.54,0.53,0.58 ; 0.6)]$} & $(1,1)$ \\
\hline 3 & {$[(0.72,0.78,0.81 ; 0.3),(0.65,0.78,0.86 ; 0.6)]$} & $(2,1)$ \\
\hline 4 & {$[(0.83,0.90,0.94 ; 0.3),(0.78,0.90,0.99 ; 0.6)]$} & $(3,1)$ \\
\hline 5 & {$[(0.95,1.06,1.1 ; 0.3),(0.91,1.06,1.14 ; 0.6)]$} & $(3,2)$ \\
\hline 6 & {$[(1.10,1.20,1.25 ; 0.3),(1.06,1.20,1.31 ; 0.6)]$} & $(3,3)$ \\
\hline 7 & {$[(1.23,1.33,1.37 ; 0.3),(1.18,1.33,1.45 ; 0.6)]$} & $(4,3)$ \\
\hline 8 & {$[(1.35,1.45,1.52 ; 0.3),(1.29,1.45,1.61 ; 0.6)]$} & $(5,3)$ \\
\hline 9 & {$[(1.48,1.57,1.62 ; 0.3),(1.43,1.57,1.71 ; 0.6)]$} & $(6,3)$ \\
\hline 10 & {$[(1.61,1.67,1.71 ; 0.3),(1.57,1.67,1.78 ; 0.6)]$} & $(6,4)$ \\
\hline
\end{tabular}

Let us now compute ${ }^{\gamma_{1,2,3}}(l)$, the optimal return on the investments in $S_{1}, S_{2}$, and $S_{3}$ for various values of $l$ as:

$$
\gamma_{1,2,3}(l)=\underset{x+y=l}{\operatorname{Max}}\left(\gamma_{1,2}(l)(+) f_{3}(x)\right)
$$

\begin{tabular}{|c|c|c|}
\hline Investment $\quad \times 10^{6}$ & $\gamma_{1,2,3}(l)$ & $\begin{array}{c}\text { Optimal Policy with } \\
S_{2} \text {,and } \\
S_{3}\end{array}$ \\
\hline 0 & 0 & $(0,0,0)$ \\
\hline
\end{tabular}

Table3. Optimal policy investments $S_{1}, S_{2}$ and $S_{3}$ 


\begin{tabular}{|c|c|c|}
\hline 1 & {$[(0.26,0.28,0.29 ; 0.3),(0.25,0.28,0.30 ; 0.6)]$} & $(1,0,0)$ \\
\hline 2 & {$[(0.49,0.53,0.55 ; 0.3),(0.45,0.53,0.58 ; 0.6)]$} & $(1,1,0)$ \\
\hline 3 & {$[(0.72,0.78,0.81 ; 0.3),(0.65,0.78,0.86 ; 0.6)]$} & $(2,1,0)$ \\
\hline 4 & {$[(0.83,0.90,0.94 ; 0.3),(0.78,0.90,0.99 ; 0.6)]$} & $(3,1,0)$ \\
\hline 5 & {$[(0.97,1.05,1.11 ; 0.3),(0.91,1.05,1.17 ; 0.6)]$} & $(3,1,1)$ \\
\hline 6 & {$[(1.10,1.20,1.25 ; 0.3),(1.06,1.20,1.30 ; 0.6)]$} & $(3,3,0)$ \\
\hline 7 & {$[(1.24,1.35,1.42 ; 0.3),(1.19,1.35,1.48 ; 0.6)]$} & $(3,3,1)$ \\
\hline 8 & {$[(1.37,1.48,1.54 ; 0.3),(1.31,1.48,1.63 ; 0.6)]$} & $(4,3,1)$ \\
\hline 9 & {$[(1.49,1.60,1.69 ; 0.3),(1.42,1.60,1.79 ; 0.6)]$} & $(5,3,1)$ \\
\hline 10 & {$[(1.62,1.72,1.79 ; 0.3),(1.56,1.72,1.89 ; 0.6)]$} & $(6,3,1)$ \\
\hline
\end{tabular}

Now, let us compute ${ }^{\gamma_{1,2,3,4}(l)}$, the optimal return on the investments in $S_{1}, S_{2}, S_{3}$, and $S_{4}$ for various values of $l_{\text {as: }}$ $\gamma_{1,2,3,4}(l)=\underset{x+y=l}{\operatorname{Max}}\left(\gamma_{1,2,3}(l)(+) f_{4}(x)\right)$

The results of these computations are given in the table below

Table4. Optimal policy investments $S_{1}, S_{2}, S_{3}$ and $S_{4}$

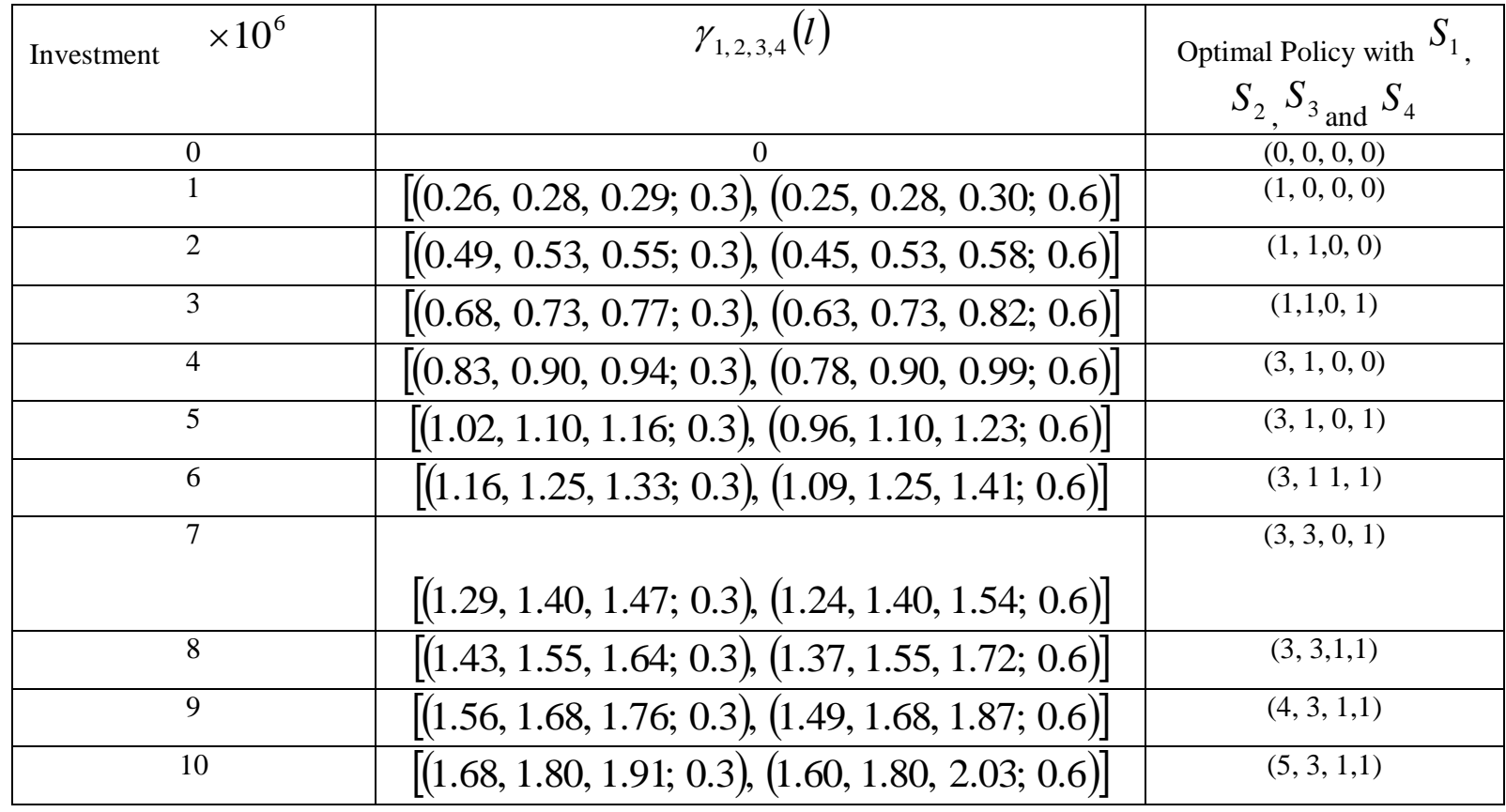

Hence, the best investment for $\$ 10$ million as computed in Table4 is:

$\$ 5.0$ million in $S_{1}$ with an optimal interval- valued fuzzy return:

$\$[(0.85,0.90,0.95 ; 0.3),(0.81,0.90,1.01 ; 0.6)]$ million

$\$ 3.0$ million in $S_{2}$ with an optimal interval- valued fuzzy return:

$\$[(0.50,0.55,0.57 ; 0.3),(0.48,0.55,0.60 ; 0.6)]$ million,

$\$ 1.0$ million in $S_{3}$ with an optimal interval- valued fuzzy return:

$\$[(0.14,0.15,0.17 ; 0.3),(0.13,0.15,0.18 ; 0.6)]$ million, and

$\$ 1.0$ million in $S_{4}$ with an optimal interval- valued fuzzy return: $\$[(0.19,0.20,0.22 ; 0.3),(0.18,0.20,0.24 ; 0.6)]$ million.

Thus, the total optimal return on a $\$ 10$ million investment is

$\$[(1.68,1.80,1.91 ; 0.3),(1.60,1.80,2.03 ; 0.6)]_{\text {million. }}$ 


\section{CONCLUSION}

In this paper, investment problem involving data in the interval- valued fuzzy numbers form instead of normal fuzzy numbers has been introduced. A dynamic programming approach has been applied to obtain interval- valued fuzzy return. The significant benefit of using such approach than the others where the decision maker facing a problem including ambiguity in the data. It is clear that planned investment is fully investigated and all options explored so as to ensure that it is aligned with the organizations business objectives and strategies directions. The process of optimization has been illustrated by a numerical example.

\section{ACKNOWLEDGEMENT}

The author are very grateful to the anonymous reviewers for his/ her insightful and constructive comments and suggestions that have led to an improved version of this paper.

\section{REFERENCES}

[1] Abel, A.B., and Eberly, J. C. (1994). A unified model of investment under uncertainty. American Economic Review, (84): 1369- 1384.

[2] Ammar,E.E., and Khalifa, H.A. (2003). Fuzzy portfolio selection problem- quadratic programming approach. Chaos, Solitons and Fractels, 18(5): 1045- 1054.

[3] Ammar, E. E., and Khalifa, H. A. (2005). Characterization of optimal solutions of uncertainty investment problem. Applied Mathematics and Computation, (18): 1045- 1054.

[4] Ammar,E.E., and Khalifa, H.A. (2015). On rough interval quadratic programming approach for minimizing the total variability in the future payments to portfolio selection problem. International Journal of Mathematical Archive, 6(1): 67- 75 Science, (17): 141-164.

[5] Ammar,E.E., and Khalifa, H.A. (2015. Solving investment problem with inexact rough onterval data through dynamic programming approach. British Journal of Mathematical \& Computer Science, 8(3): 238- 245.

[6] Chiang, J.(2005). The optimal solution of the transportation problem with fuzzy demand and fuzzy product. Journal of Information Science and Engineering, 21(2): 439- 451.

[7] Dubois, D., and Prade, H. (1980). Fuzzy Sets and Systems: Theory and Applications, Academic Press, New York.

[8] Hargitay, S. (1985). The portfolio problem in the property investment context. Journal of Valuation, 3(2): 117- 125.

[9] Hu, J. Q., and Szmerekovsky, J. (2016). Project portfolio selection: A newsvendor approach. Journal of Decision Science, DOI 10, 1111/ deci, 12214.
[10] Jana, P., Roy, T.K., and Mazunder, S. K. (2009). Multiobjective possibilities model for portfolio selection with transaction cost. Journal of Computational and Applied Mathematics, (228):188- Fuzzy Optimization and Decision Making(12):101- 122.

[11] Kahraman, C., Ruan, D., and Bozdag, E.C. (2001). Optimization of multilevel investments using dynamic programming based on fuzzy cash flows. Annals of Operations Research, (168): 169-179.

[12] Kaufmann, A.,. and Gupta, M. M. (1988). Fuzzy Mathematical Models in Engineering and Management Science. Elsevier Science Publishing Company INC, New York.

[13] Khalifa, H. A., and ZeinEldein, R. A. (2014). Fuzzy programming approach for portfolio selection problems selection problems with fuzzy coefficients. International Journal of Scientific Knowledge, 4(7): 40- 47.

[14] Meza, D. D., and Webb, C. D. (1987). Too much investment: A problem of symmetric information. The Quarterly Journal of Economics, 102(2): 281- 292.

[15] Modarros, M., Mohammed, F., and Reza, Y. M. (2014). A dynamic programming approach for investment problem with stochastic number of investment chances. 10th International Industrial Engineering Conference.

[16] Sirbilaze, G., Khutsishvili, I., and Ghvaberidze, B. (2014). Multistage decision- making fuzzy methodology for optimal investments based on expert's evaluations. European Journal of Operations Research, (232): 169. 177

[17] Suh, S. (2016). A combination rule for portfolio selection with transaction. International Review of Finance, 16(3): 393- 402 .

[18] Tahar, B. I., Soner, M. H., and Touzi, N. (2007). The dynamic programming equation for the problem of optimal investment- under capital gains taxes. Society for Industrial and Applied Mathematics, (46): 1779- 1801.

[19] Xu, M. (2014). Optimization of fuzzy production and financial investment planning problems. Journal of Uncertain Systems, (8): 101- 108.

[20] Yahaya, A. (2011). On numerical solution for optimal allocation of investment funds in portfolio selection problem. CBN Journal of Applied Statistics, 3(2):1- 15.

[21] Yahaya, A., Abubakar, A. H., and Gabar, J. (2011). Statistical analysis on the advantages of portfolio diversification. International Journal of Pure and Applied Science and Technology, 7(2):98- 107.

[22] Zadeh,L. A. (1965). Fuzzy sets. Information Control, (8):338- 353 